\title{
Dyslipidemia in Subclinical Hypothyroidism: A Case-Control Study
}

\author{
Bayar Qasim $^{1 *}$, Sardar Arif ${ }^{2}$, Ayad Mohammed ${ }^{2}$ and Rezvan Abduljabbar ${ }^{3}$ \\ ${ }^{1}$ Department of medicine, College of Medicine, University of Duhok, Duhok, Iraq. \\ ${ }^{2}$ Department of surgery, College of Medicine, University of Duhok, Duhok, Iraq. \\ ${ }^{3}$ Hematology Oncology Center, Azadi Teaching Hospital, Duhok Directorate of health, Iraq.
}

Received: December 20, 2017; Accepted: January 03, 2018; Published: January 12, 2018

*Corresponding author: Bayar Qasim, University of Duhok School of Medicine, Azadi Teaching Hospital, 8 Nakhoshkhana Road, 1014 AM, Dohuk City, DUHOK, Iraq. ORCID: 0000-0002-0994-7861; Tel: 009647507599548 ;Email: Bayarsabc@gmail.com

\begin{abstract}
Subclinical hypothyroidism (SCH) affects $7.5-8.5 \%$ of women and $2.8-4.4 \%$ of men. Overt hypothyroidism is characterized by dyslipidemia, however controversy persists regarding the lipids level in SCH and its clinical significance. Recent evidence shows that T4 replacement therapy may improve lipid profile. The aim of this study is to assess the prevalence of dyslipidemia in $\mathrm{SCH}$, this first study to assess dyslipidemia among patients with $\mathrm{SCH}$ in Duhok, Iraq is a case-control study, comparing 60 patients diagnosed with subclinical hypothyroidism to 60 healthy individuals (matched for age and gender). The study conducted at the endocrine clinic at Azadi Teaching Hospital in Duhok Governorate, Kurdistan Region, Iraq from $1^{\text {st }}$ June 2016 to $1^{\text {st }}$ June 2017. Dyslipidemia was much more prevalent in patients with $\mathrm{SCH}$ compared to control group $(\mathrm{p}<0.001)$. In further analysis of dyslipidemia total cholesterol and triglyceride levels were statistically higher among cases in comparison to controls $(p<0.001)$ for both. LDL level was higher among cases in comparison to controls but did not reach statistical significance $(p=0.087)$. While there was significant difference regarding HDL level among female gender cases and controls $(p=0.003)$, there was no significant difference regarding difference in HDL level among male gender cases and controls $(p=0.653)$.SCH is considered atherogenic condition as it increases dyslipidemia and it increases overall cardiovascular risk. It's important to assess lipid profile and CVS risk in these patients and to treat with levothyroxine when it's clinically applicable
\end{abstract}

Keywords: Dyslipidemia, Subclinical hypothyroidism (SCH), Case control study.

\section{Introduction}

Thyroid disorders may occur at any stage of life. They are more commonly encountered in the mid age and adulthood. Thyroid hormones influence nearly all major metabolic pathways. Their most obvious and well-known action is the increase in basal energy expenditure obtained by acting on protein, carbohydrate and lipid metabolism. The lipid metabolism is more influenced by the thyroid hormone [1]. Thyroid hormones are of vital importance in maintaining the initial level of phospholipids in cell membranes and fatty acids composition of the lipids [2]. Triiodothyronine (T3) plays a critical role in lipid metabolism by regulating genes involved in lipogenesis and lipolysis $[3,4]$.
Hypothyroidism results from reduced secretion of both thyroxine (T4) and T3. Biochemically decrease in T4 and T3 concentrations leads to increased serum thyroid stimulating hormone (TSH) level[5,6].Overt hypothyroidism is characterized by hypercholesterolemia and a marked increase in LDL because of a decreased fractional clearance of LDL by a reduced number of LDL receptors in the liver. However controversy persists regarding the lipid levels in subclinical hypothyroidism( $\mathrm{SCH}$ ) and its clinical significance $[1,7]$.

Asymptomatic patients with raised TSH and normal FT4 concentration are known as subclinical hypothyroid. SCH is mild thyroid disorder if left untreated leads to overt hypothyroidism in many cases. Patients of SCH are mostly asymptomatic or have minimal symptoms. Thus, $\mathrm{SCH}$ is solely a laboratory diagnosis [5]. Although clinical diagnosis of thyroid dysfunction is suspected by the presence of a small goiter[8].It is a common condition affecting $6-17 \%$ of the general population [9].

The incidence of SCH is more common in women than men, almost twice [10]. Worldwide prevalence of SCH is found to be 7.58.5\% in women and $2.8-4.4 \%$ in men [11]. The diagnosis is based upon biochemical testing which is done by chemiluminiscence technique. The normal TSH range is $0.4-4.5 \mathrm{mIU} / \mathrm{L} \mathrm{TSH}[5]$.

Subclinical hypothyroidism is a risk factor for increased incidence of coronary events, increased rates of congestive heart failure and lipid abnormalities. Dyslipidemia is one of many modifiable and non-modifiable cardiovascular risk factors like diastolic hypertension, impaired endothelial function, increased arterial stiffness, and coagulation parameters and elevated C-reactive protein levels are associated with subclinical hypothyroidism[11].

The Pathophysiology lies behind the lipid alterations of overt and SCH includes elevations in serum total cholesterol due to changes in the synthesis, metabolism, and mobilization of lipids in liver and adipose tissue. High TSH level induces the hepatic expression of hydroxy methyl glutaryl coenzyme A reductase, which results in increased cholesterol synthesis [12]. In hypothyroid patients the most frequent lipid abnormality is 
hypercholesterolemia. Elevation of very low density lipoproteins (VLDL) and high density lipoproteins (HDL) have also been reported. Plasma triglycerides are increased because of an enhanced esterification of fatty acids at hepatic level [1].

In recent population based surveys $\mathrm{SCH}$ emerged as an independent risk factor for aortic atherosclerosis and myocardial infarction $[13,14]$. Many of the perimenopausal symptoms are similar to symptoms of hypothyroidism, so evaluation of thyroid profile in these patients might show the presence of SCH which can be masked by perimenopausal symptoms[15].

Moreover, SCH may progress to overt hypothyroidism. The rate of progression is higher with the concomitant presence of thyroperoxidase antibodies or higher levels of TSH [16]. After treatment with small doses of levothyroxine there was a significant decrease of total cholesterol, non-HDL-C, LDL-C, and LDL-C to HDL-C values [17]. Recent evidence also shows that T4 replacement therapy may improve lipid profile in the cases of SCH[18].

\section{Patients And Methods}

The population of this case control study consisted of a total 120 individuals, 60 patients diagnosed with SCH, while 60 healthy individuals in control group (matched for age and gender), from $1^{\text {st }}$ June 2016 to $1^{\text {st }}$ June 2017, who come for follow up in the endocrine clinic at Azadi General Teaching Hospital. The informed consent was taken from every patient after full explanation of the study; this all was performed under medical ethics. The detailed history of all such patients was taken and complete physical and relevant clinical examination was performed. A speciallydesigned questionnaire was used to obtain information from participants.

The study included patients who fulfill criteria of SCH, when TSH is more than $5.0 \mathrm{mIU} / \mathrm{L}$ and free T3, free T4 are at the lower end of the reference range repeated twice at least 6 weeks apart. While exclusion criteria include any factors altering TFT[19] which include; pregnancy, drugs like estrogen-containing oral contraceptives, amiodarone, phenytoin and steroids, liver and renal disorders, previous Thyroid disorders or family history of thyroid diseases, smoking, history of recent surgery [20] and history of acute illness as critical illness is often associated with alterations in thyroid hormone concentrations in patients with no previous history of thyroid disease[21, 22]. Patients on lipid lowering agents were not included. Those patients who are older in age, higher TSH $(>6)$ used to define $\mathrm{SCH}$, while patients older than 65 years excluded from study.

Dyslipidemia cut points based on AACE guidelines [23] which includes; total cholesterol desirable $<200 \mathrm{mg} / \mathrm{dl}$, Borderline high 200- 239, High > $239 \mathrm{mg} / \mathrm{dl}$. High density lipoprotein cholesterol: dyslipidemic Low $<40 \mathrm{mg} / \mathrm{dl}$ in males, $<50 \mathrm{mg} / \mathrm{dl}$ in females. Low density lipoprotein -cholesterol: Optimal $<100$ $\mathrm{mg} / \mathrm{dl}$, near optimal 100-129 mg/dL, Borderline high 130-159 mg/dl, High $160-189 \mathrm{mg} / \mathrm{dl}$, very high > $189 \mathrm{mg} / \mathrm{dl}$. Triglyceride: Normal < $150 \mathrm{mg} / \mathrm{d}$, High 150-199 mg/dl, Hypertriglyceridemic 200-499 mg/dl, very high $>499 \mathrm{mg} / \mathrm{dl}$.
All data were analyzed using the Statistical Package for Social Science (SPSS); Spearman's correlation test was used for comparison of IGF1 levels before and after treatment, while paired student t-test was used to assess differences in $\mathrm{GH}$ between the groups. P values less than 0.05 were considered significant. All data were analyzed using the Statistical Package for Social Science (SPSS); Significance of association between various risk factors was assessed using Chi-square test. Level of statistical significance was set at $<0.05$.

\section{Results}

The median age of patients at presentation was 47.3 (SD of 9.9), with majority of patients between 30-39 years as shown in Figure 1. Male constitutes 32 (52.5\%), female constitutes $29(47.5 \%)$ as shown in Figure 2. majority of patients have no co morbidities (97\%), while 3\% of cases have associated DM as shown in Figure 3.

Prevalence of dyslipidemia as general was higher among subclinical hypothyroidism cases $(\mathrm{TSH}>5)$ in comparison to control group $(\mathrm{TSH} \leq 5)(\mathrm{p}<0.001)$, dyslipidemia was increased as level of TSH increased as shown in Figures 3, 4 and 5. In further analysis of dyslipidemia total cholesterol level was statistically higher among cases in comparison to controls ( $p<0.001$ )as shown in Figure 6. LDL level was higher among cases in comparison to controls, however it didn't reach statistical significance $(\mathrm{p}=0.087)$ as shown in Figure 7. Triglyceride level was also statistically higher among cases in comparison to controls $(p<0.001)$ as shown in Figure 8: Prevalence of high triglyceride level among cases $(\mathrm{TSH}>5)$ and Controls $(\mathrm{TSH} \leq 5)(\mathrm{p}<0.001)$.

Regarding HDL there was gender difference, as there was no significant difference regarding difference in HDL level among male gender cases and controls ( $p=0.653)$, as shown in Figure 9, while there was significant difference regarding HDL level among female gender cases and controls ( $p=0.003)$, as shown in Figure 10 .

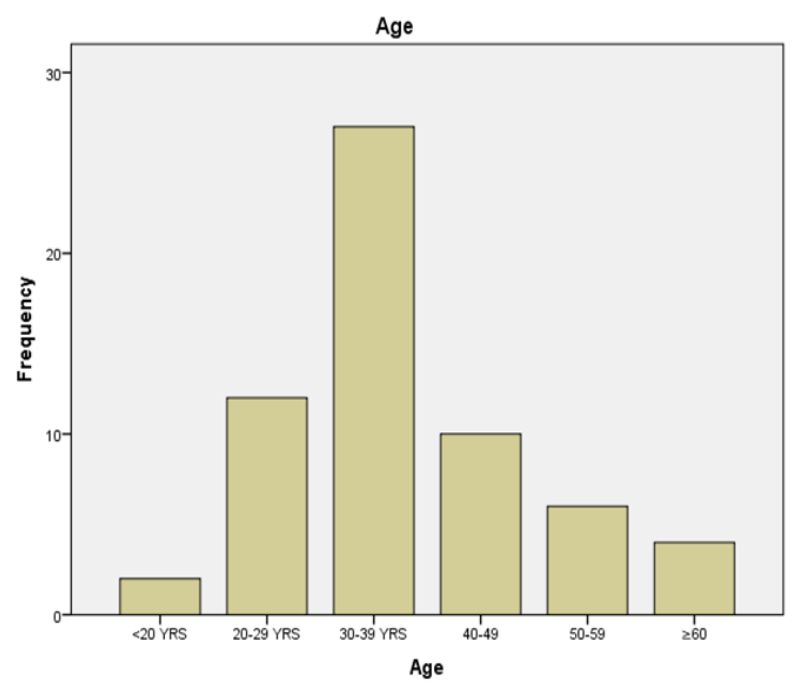

Figure 1: Age of patients involved in study, majority of participants were between $30-39$ years $(44.3 \%)$, followed by age of $20-29$ years $(19.7 \%)$. 


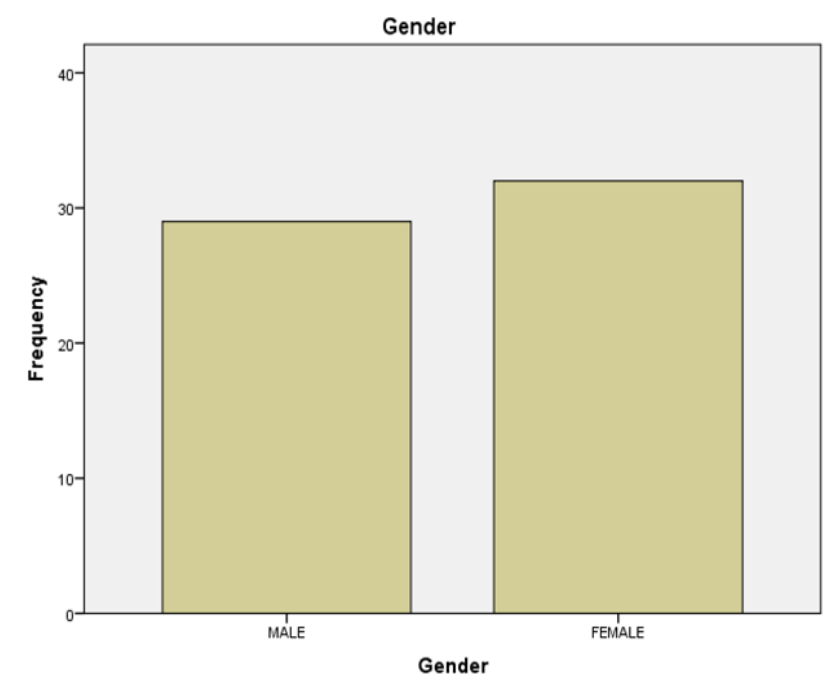

Figure 2: Gender of patients involved in study, male constitutes 32 (52.5\%), female constitutes 29 (47.5\%).

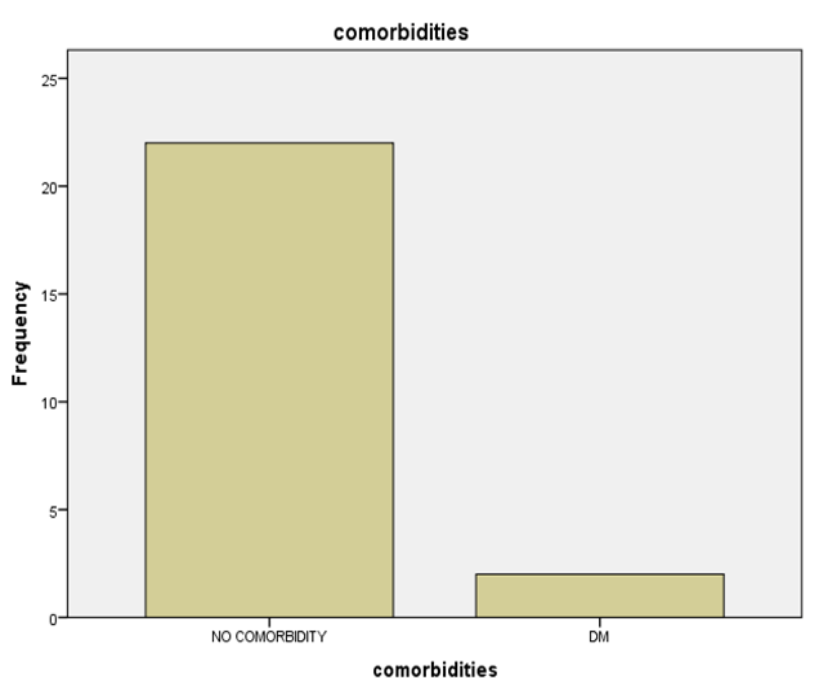

Figure 3: Co morbidities associated with subclinical hypothyroidism, majority of patients have no co morbidities (97\%), while $3 \%$ of cases have associated DM.

\section{Discussion}

Consequences of SCH include risk of progression to overt hypothyroidism, dyslipidemia, and adverse effects on cardiovascular system, which include diastolic dysfunction, ischemic heart disease (IHD), heart failure and the overall increase in mortality.SCH can be transient and full recovery occurs subsequently [24-27], therefore, careful patient selection is crucial, and treatment is a real challenge in clinical practice.

There are many studies which found positive relation between SCH and IHD[28-35], the presence of dyslipidemia may be one of explanations of higher incidence of IHD in this group of patients, as it is well known that dyslipidemia predispose to atherosclerosis. However there are many studies which did not

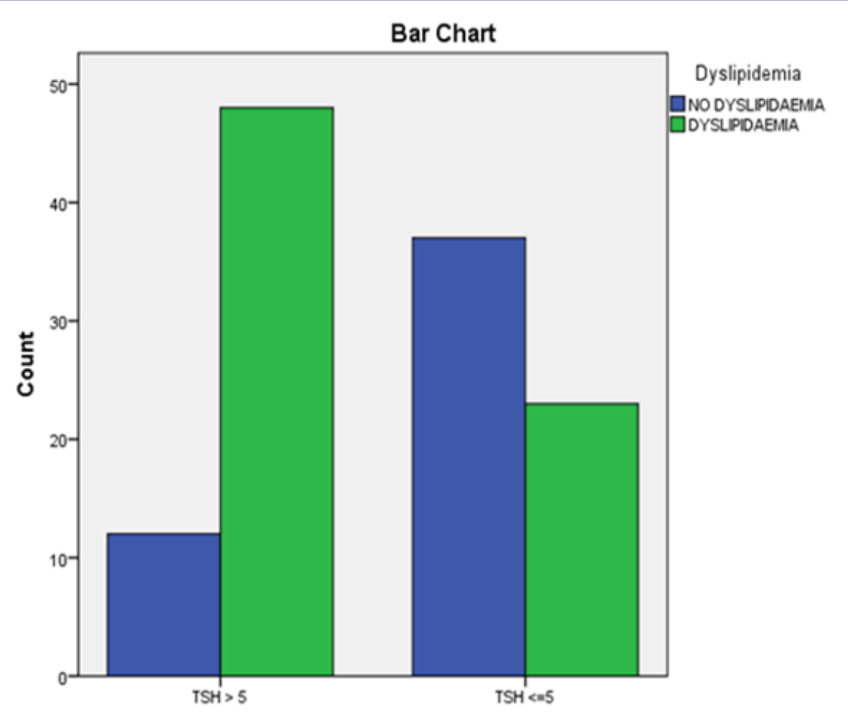

Figure 4: Prevalence of Dyslipidemia among cases $(\mathrm{TSH}>5)$ and Controls $(\mathrm{TSH} \leq 5)(\mathrm{p}<0.001)$.

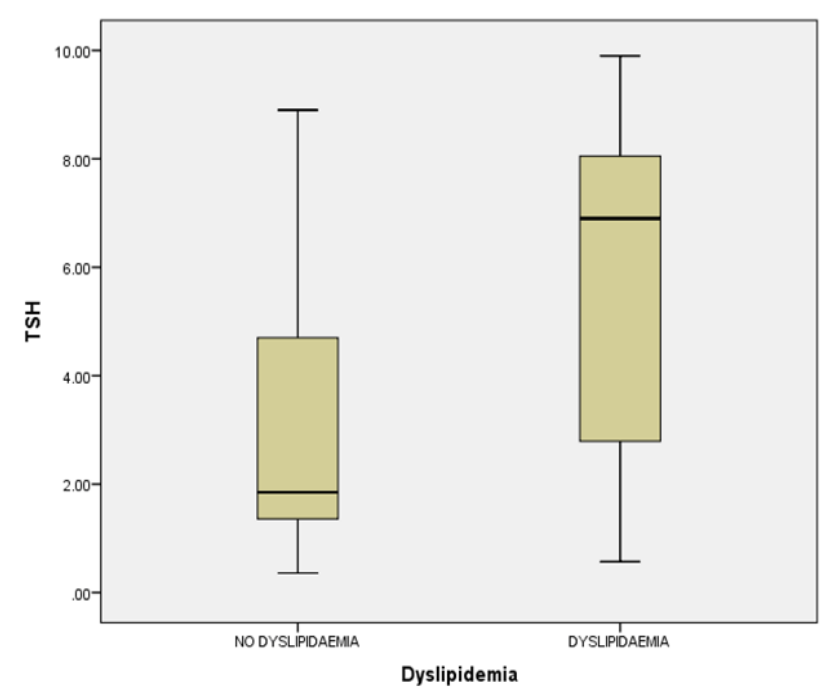

Figure 5: Dyslipidemia prevalence according to TSH level, the prevalence of dyslipidemia increased as level of TSH increased.

find a positive correlation between SCH and dyslipidemia[16, 36, 37].

Our study shows a strong association between SCH and dyslipidemia as dyslipidemia was much more prevalent in patients with SCH in comparison to control group and this was in accordance with results of many other studies, which also find the same[38-43].

In further analysis of dyslipidemia total cholesterol and triglyceride levels were statistically higher among cases in comparison to controls for both, this in accordance to many other studies[44]. LDL level was higher among cases in comparison to controls; however it did not reach statistical significance. While there was significant difference regarding HDL level among female gender cases and controls, there was no significant 


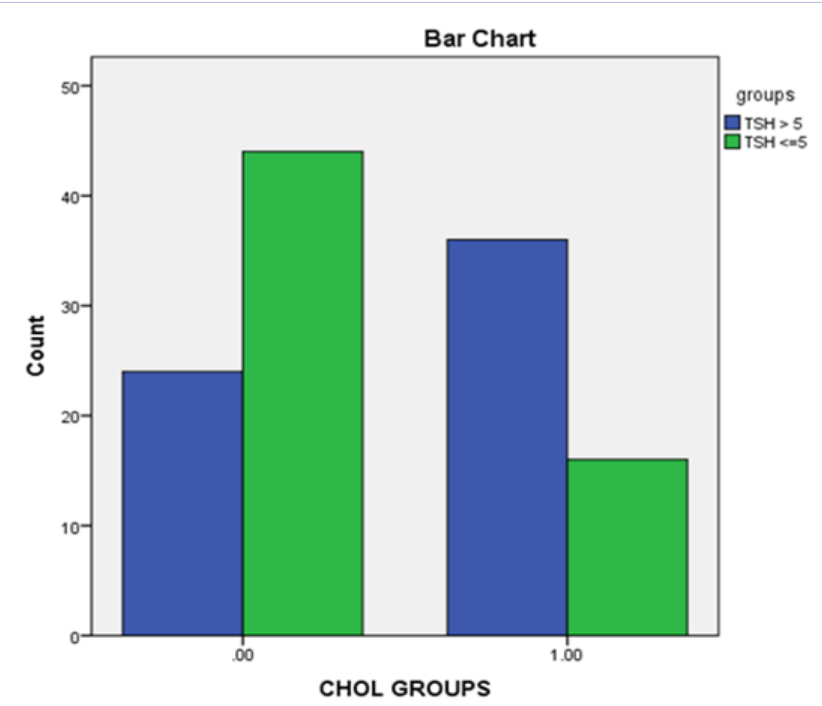

Figure 6: Prevalence of high total cholesterol level among cases $(\mathrm{TSH}>5)$ and Controls $(\mathrm{TSH} \leq 5)(\mathrm{p}<0.001)$.

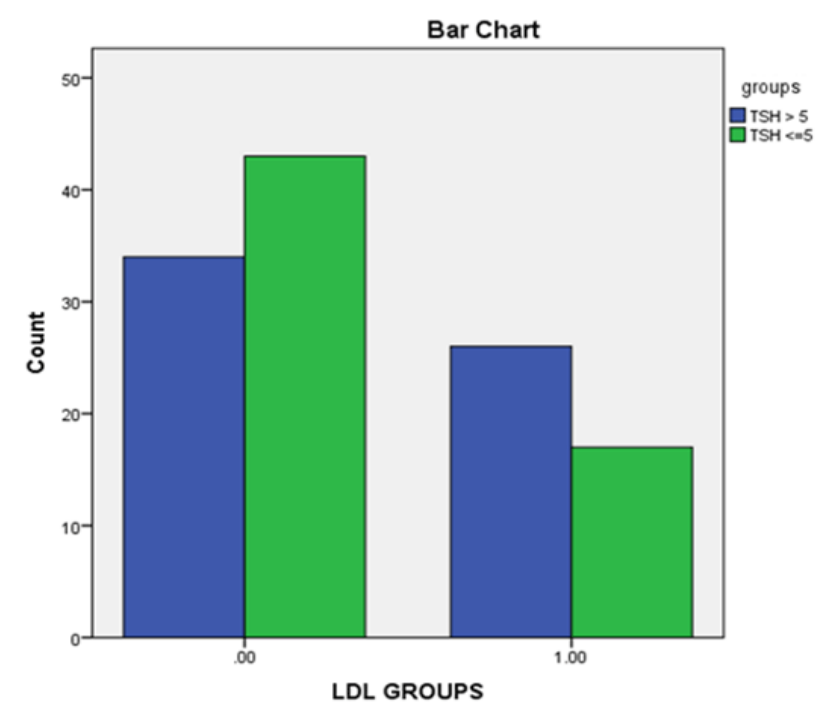

Figure 7: Prevalence of high LDL level among cases $(\mathrm{TSH}>5)$ and Controls $(\mathrm{TSH} \leq 5)(\mathrm{p}=0.087)$

difference regarding difference in HDL level among male gender cases and controls, this may be reflection on the difference in pattern of dyslipidemia in Iraqi populations.

Furthermore there is emerging evidence that treatment with thyroxin lowers serum lipid in SCH that is why it is important to treat cases of $\mathrm{SCH}$ with dyslipidemia. Even small reductions in levels of total cholesterol, triglyceride, and LDL result in significant reduction in cardiovascular morbidity $[45,46]$.

\section{Conclusion}

In conclusion, $\mathrm{SCH}$ is considered atherogenic condition as it increases dyslipidemia and it increases overall cardiovascular risk. Treatment of SCH with levothyroxine improves quality of life, dyslipidemia, and overall cardiovascular risk. It is reasonable to assess lipid profile and CVS risk in these patients and to treat

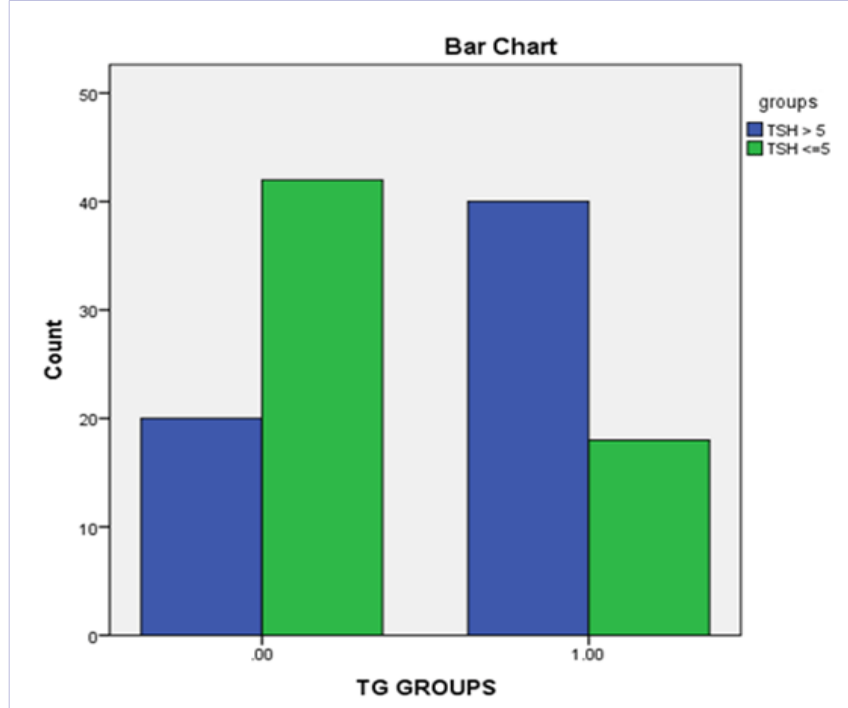

Figure 8: Prevalence of high triglyceride level among cases $(\mathrm{TSH}>5$ ) and Controls $(\mathrm{TSH} \leq 5)(\mathrm{p}<0.001)$.

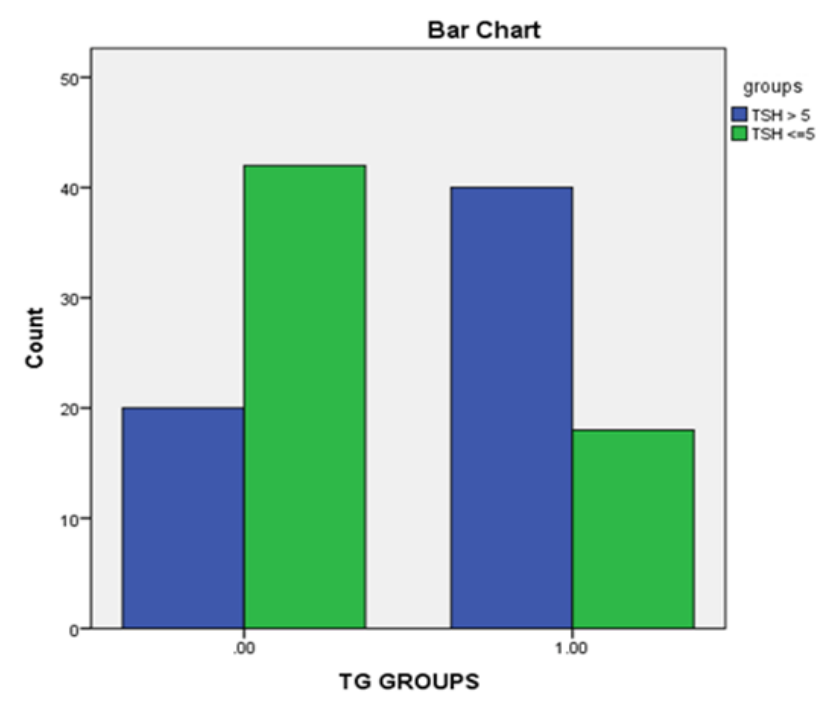

Figure 9: Prevalence of high HDL level among male gender cases $(\mathrm{TSH}>5)$ and Controls $(\mathrm{TSH} \leq 5)(\mathrm{p}=0.653)$.

with levothyroxine when it's clinically applicable.

\section{Acknowledgements}

\section{Compliance with Ethical Standards}

This study was not funded by any specific organization.

\section{Disclosure}

The authors declare that they have no conflict of interest.

\section{Ethical approval}

All procedures performed in studies involving human participants were in accordance with the ethical standards of the institutional and/or national research committee and with the 1964 Helsinki declaration and its later amendments or comparable ethical standards. 


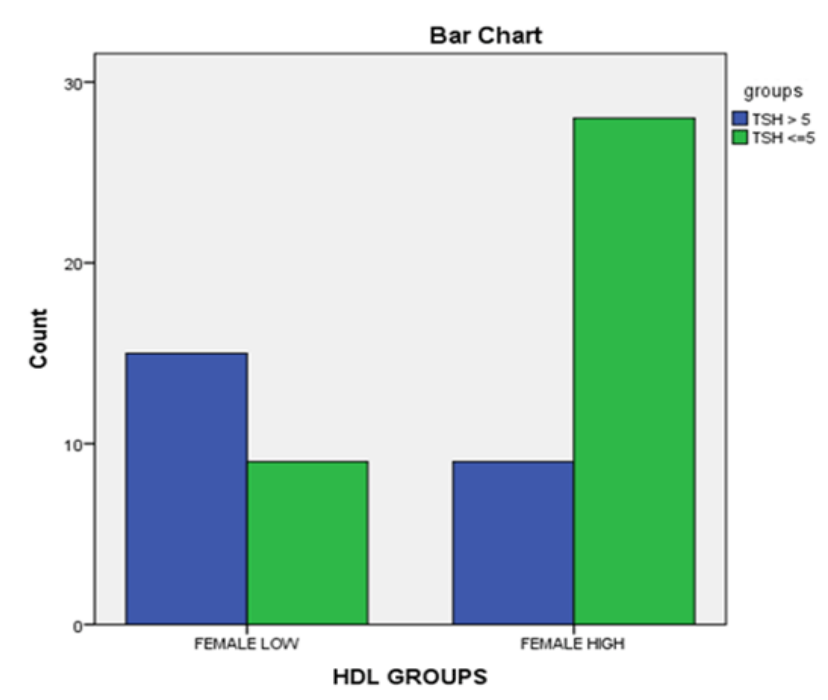

Figure 10: Prevalence of high HDL level among female gender cases $(\mathrm{TSH}>5)$ and Controls $(\mathrm{TSH} \leq 5)(\mathrm{p}=0.003)$.

\section{References}

1. Pucci E, Chiovato L, Pinchera A. Thyroid and lipid metabolism. Int J Obes Relat Metab Disord. 2000;24(2):S109-112.

2. Prasad R, Kumar V. Thyroid hormones increase Na+-Pi co-transport activity in intestinal brush border membrane: role of membrane lipid composition and fluidity. Mol Cell Biochem. 2005;278(1-2):195-202. Doi: 10.1007/s11010-005-7498-7

3. Zhu X, Cheng SY. New insights into regulation of lipid metabolism by thyroid hormone.Curr Opin Endocrinol Diabetes Obes. 2010;17(5):408413. Doi: 10.1097/MED.0b013e32833d6d46

4. Axelband F, Dias J, Ferrao FM, Einicker-Lamas M. Nongenomic signaling pathways triggered by thyroid hormones and their metabolite 3-iodothyronamine on the cardiovascular system. J Cell Physiol. 2011;226(1):21-28.

5. Surks MI, Ortiz E, Daniels GH, Sawin CT, Col NF, Cobin RH, et al. Subclinical thyroid disease: scientific review and guidelines for diagnosis and management. JAMA. 2004;291(2):228-238. Doi: 10.1001/jama.291.2.228

6. Tunbridge WM, Evered DC, Hall R, Appleton D, Brewis M, Clark F, et al. The spectrum of thyroid disease in a community: the Whickham survey. Clin Endocrinol (Oxf). 1977;7(6):481-493.

7. Jiskra J, Limanova Z, Antosova M. [Thyroid diseases, dyslipidemia and cardiovascular risk]. Vnitr Lek. 2007;53(4):382-385.

8. Shah SN, Joshi SR.Think thyroid. J Assoc Physicians India. 2011;59(Suppl 6):15-20.

9. Helfand M. Screening for subclinical thyroid dysfunction in nonpregnant adults: a summary of the evidence for the U.S. Preventive Services Task Force. Ann Intern Med. 2004;140(2):128-141.

10.Canaris GJ, Manowitz NR, Mayor G, Ridgway EC. The Colorado thyroid disease prevalence study. Arch Intern Med. 2000;160(4):526-534.

11.Biondi B, Cooper DS. The clinical significance of subclinical thyroid dysfunction. Endocr Rev. 2008;29(1):76-131. Doi: 10.1210/er.20060043
12.Choi JW, Choi HS. The regulatory effects of thyroid hormone on the activity of 3-hydroxy-3-methylglutaryl coenzyme A reductase. Endocr Res. 2000;26(1):1-21.

13.Neves C, Alves M, Medina JL, Delgado JL. Thyroid diseases, dyslipidemia and cardiovascular pathology. Rev Port Cardiol. 2008;27(10):12111236.

14.Papi G, Uberti ED, Betterle C, Carani C, Pearce EN, et al. Subclinical hypothyroidism. Curr Opin Endocrinol Diabetes Obes. 2007;14(3):197208.

15.Flynn RW, Bonellie SR, Jung RT, MacDonald TM, Morris AD, Leese GP. Serum thyroid-stimulating hormone concentration and morbidity from cardiovascular disease and fractures in patients on long-term thyroxine therapy. J Clin Endocrinol Metab. 2010;95(1):186-193. Doi: $10.1210 /$ jc. $2009-1625$

16.Vanderpump MP, Tunbridge WM, French JM, Appleton D, Bates D, et al. The incidence of thyroid disorders in the community: a twentyyear follow-up of the Whickham Survey. Clin Endocrinol (Oxf). 1995;43(1):55-68.

17.Iqbal A, Jorde R, Figenschau Y. Serum lipid levels in relation to serum thyroid-stimulating hormone and the effect of thyroxine treatment on serum lipid levels in subjects with subclinical hypothyroidism: the Tromso Study. J Intern Med. 2006;260(1):53-61.

18.Tagami T, Tamanaha T, Shimazu S, Honda K, Nanba K, et al. Lipid profiles in the untreated patients with Hashimoto thyroiditis and the effects of thyroxine treatment on subclinical hypothyroidism with Hashimoto thyroiditis. Endocr J. 2010;57(3):253-258.

19.Tziomalos K, Charsoulis F. Endocrine effects of tobacco smoking. Clin Endocrinol (Oxf). 2004;61(6):664-674.

20.Desborough JP. The stress response to trauma and surgery. Br J Anaesth. 2000;85(1):109-117.

21.DeGroot LJ. "Non-thyroidal illness syndrome" is functional central hypothyroidism, and if severe, hormone replacement is appropriate in light of present knowledge. J Endocrinol Invest. 2003;26(12):11631170 .

22.Adler SM, Wartofsky L. The nonthyroidal illness syndrome. Endocrinol Metab Clin North Am. 2007;36(3):657-672.

23.Jellinger PS, Smith DA, Mehta AE, Ganda O, Handelsman Y, et al. American Association of Clinical Endocrinologists' Guidelines for Management of Dyslipidemia and Prevention of Atherosclerosis. Endocr Pract. 2012;18 (Suppl 1):1-78.

24.Diez JJ, Iglesias P. Spontaneous subclinical hypothyroidism in patients older than 55 years: an analysis of natural course and risk factors for the development of overt thyroid failure. J Clin Endocrinol Metab. 2004;89(10):4890-4897. Doi: 10.1210/jc.2003-032061

25.Huber G, Staub JJ, Meier C, Mitrache C, Guglielmetti M, et al. Prospective study of the spontaneous course of subclinical hypothyroidism: prognostic value of thyrotropin, thyroid reserve, and thyroid antibodies. J Clin Endocrinol Metab. 2002;87(7):3221-3226. Doi: 10.1210/jcem.87.7.8678

26.Utiger RD. Vanishing hypothyroidism. N Engl J Med. 1992;326(8):5132518.

27.Meyerovitch J, Rotman-Pikielny P, Sherf M, Battat E, Levy Y, Surks MI. Serum thyrotropin measurements in the community: five-year followup in a large network of primary care physicians. Arch Intern Med. 2007;167(14):1533-1538. Doi: 10.1001/archinte.167.14.1533 
28.0chs N, Auer R, Bauer DC, Nanchen D, Gussekloo J, et al. Meta-analysis: subclinical thyroid dysfunction and the risk for coronary heart disease and mortality. Ann Intern Med. 2008;148(11):832-845

29.Razvi S, Shakoor A, Vanderpump M, Weaver JU, Pearce SH. The influence of age on the relationship between subclinical hypothyroidism and ischemic heart disease: a metaanalysis. J Clin Endocrinol Metab. 2008;93(8):2998-3007. Doi: 10.1210/jc.2008-0167

30.McQuade C, Skugor M, Brennan DM, Hoar B, Stevenson C, Hoogwerf BJ. Hypothyroidism and moderate subclinical hypothyroidism are associated with increased all-cause mortality independent of coronary heart disease risk factors: a PreCIS database study. Thyroid. 2011;21(8):837-843. Doi: 10.1089/thy.2010.0298

31.Razvi S, Weaver JU, Butler TJ, Pearce SH. Levothyroxine treatment of subclinical hypothyroidism, fatal and nonfatal cardiovascular events, and mortality. Arch Intern Med. 2012;172(10):811-817. Doi: 10.1001/ archinternmed.2012.1159

32.Rodondi N, den Elzen WP, Bauer DC, Cappola AR, Razvi S, et al Subclinical hypothyroidism and the risk of coronary heart disease and mortality. JAMA. 2010;304(12):1365-1374. Doi: 10.1001/ jama.2010.1361

33.Razvi S, Weaver JU, Vanderpump MP, Pearce SH. The incidence of ischemic heart disease and mortality in people with subclinical hypothyroidism: reanalysis of the Whickham Survey cohort. J Clin Endocrinol Metab. 2010;95(4):1734-1740. Doi: 10.1210/jc.2009-1749

34.Gencer B, Collet TH, Virgini V, Auer R, Rodondi N. Subclinical thyroid dysfunction and cardiovascular outcomes among prospective cohort studies. Endocr Metab Immune Disord Drug Targets. 2013;13(1):4-12.

35.Tseng FY, Lin WY, Lin CC, Lee LT, Li TC, et al. Subclinical hypothyroidism is associated with increased risk for all-cause and cardiovascular mortality in adults. J Am Coll Cardiol. 2012;60(8):730-737. Doi: 10.1016/j.jacc.2012.03.047

36. Hollowell JG, Staehling NW, Flanders WD, Hannon WH, Gunter EW, Spencer CA et al. Serum TSH, T(4), and thyroid antibodies in the United States population (1988 to 1994): National Health and Nutrition Examination Survey (NHANES III). J Clin Endocrinol Metab. 2002;87(2):489-499.

37.Vierhapper H, Nardi A, Grosser P, Raber W, Gessl A. Low-density lipoprotein cholesterol in subclinical hypothyroidism. Thyroid. 2000;10(11):981-984. Doi: 10.1089/thy.2000.10.981
38.Monzani F, Caraccio N, Kozakowa M, Dardano A, Vittone F, et al. Effect of levothyroxine replacement on lipid profile and intima-media thickness in subclinical hypothyroidism: a double-blind, placebo- controlled study. J Clin Endocrinol Metab. 2004;89(5):2099-2106. Doi: 10.1210/ jc.2003-031669

39.Kvetny J, Heldgaard PE, Bladbjerg EM, Gram J. Subclinical hypothyroidism is associated with a low-grade inflammation, increased triglyceride levels and predicts cardiovascular disease in males below 50 years. Clin Endocrinol (0xf). 2004;61(2):232-238. Doi: 10.1111/j.1365-2265.2004.02088.x

40.Hak AE, Pols HA, Visser TJ, Drexhage HA, Hofman A, Witteman JC. Subclinical hypothyroidism is an independent risk factor for atherosclerosis and myocardial infarction in elderly women: the Rotterdam Study. Ann Intern Med. 2000;132(4):270-278.

41.Imaizumi M, Akahoshi M, Ichimaru S, Nakashima E, Hida A, et al. Risk for ischemic heart disease and all-cause mortality in subclinical hypothyroidism. J Clin Endocrinol Metab. 2004;89(7):3365-3370. Doi: $10.1210 /$ jc. 2003-031089

42.Bindels AJ, Westendorp RG, Frolich M, Seidell JC, Blokstra A, Smelt AH. The prevalence of subclinical hypothyroidism at different total plasma cholesterol levels in middle aged men and women: a need for casefinding? Clin Endocrinol (Oxf). 1999;50(2):217-220.

43.Kanaya AM, Harris F, Volpato S, Perez-Stable EJ, Harris T, Bauer DC. Association between thyroid dysfunction and total cholesterol level in an older biracial population: the health, aging and body composition study. Arch Intern Med. 2002;162(7):773-779.

44.Bandyopadhyay SK, Basu AK, Pal SK, Roy P, Chakrabarti S, et al. A study on dyslipidaemia in subclinical hypothyroidism. J Indian Med Assoc. 2006;104(11):622-624, 626.

45.Tanis BC, Westendorp GJ, Smelt HM. Effect of thyroid substitution on hypercholesterolaemia in patients with subclinical hypothyroidism: a reanalysis of intervention studies. Clin Endocrinol (Oxf). 1996;44(6):643-649.

46.Danese MD, Ladenson PW, Meinert CL, Powe NR. Clinical review 115 effect of thyroxine therapy on serum lipoproteins in patients with mild thyroid failure: a quantitative review of the literature. J Clin Endocrinol Metab. 2000;85(9):2993-3001. Doi: 10.1210/jcem.85.9.6841 